\title{
Caracterização Física e Térmica de Compósito de Poliuretano Derivado de Óleo de Mamona Associado com Partículas de Bambu
}

\author{
Nelson P. Marinho, Eduardo M. Nascimento \\ Programa de Pós-Graduação em Engenharia Mecânica e de Materiais, UTFPR \\ Silvana Nisgoski \\ Departamento de Engenharia e Tecnologia Florestal, UFPR \\ Washington L. E. Magalhães \\ Embrapa Florestas, Embrapa \\ Salvador C. Neto \\ Instituto de Química de São Carlos, USP \\ Elaine C. Azevedo \\ Departamento de Física, UTFPR
}

\begin{abstract}
Resumo: Compósitos de resina Poliuretana (PU) derivada de óleo de mamona e partículas de bambu (Dendrocalamus giganteus) foram preparados com 10, 15 e $20 \%$ em peso de PU pelo processo de prensagem. O objetivo do presente estudo foi criar uma solução para aproveitar resíduos da manufatura do bambu, minimizando impactos negativos ao meio ambiente, adicionando-lhe uma resina que não contém compostos orgânicos voláteis (COV). A sua caracterização foi feita através de análises físicas e termogravimetria. A associação de PU com partículas de bambu produziu efeitos esperados como a diminuição no teor de umidade, inchamento e absorção de água com o aumento do percentual de PU. Nos ensaios de dureza Shore D obteve-se um aumento gradual da rigidez superficial com o acréscimo em percentual de resina PU.
\end{abstract}

Palavras-chave: Poliuretano, óleo de mamona, bambu, compósitos.

\section{Physical and Thermal Characterization of Polyurethane Based on Castor Oil Composite with Bamboo Particles}

Abstract: Composites of Polyurethane (PU) resin derived from castor oil and bamboo particles (Dendrocalamus giganteus) were prepared by pressing with 10, 15 and $20 \%$ weight of PU. The aim of this study was to develop a new application of wastes from bamboo manufacture, minimizing the negative impact to the environment, adding a resin free of volatile organic compounds (COV). The composite characterization was performed with physical and thermogravimetric analysis. The association of PU and bamboo particles produced the expected effects, including a decrease in moisture content, swelling and water absorption as PU percentage increased. The Shore D hardness increased with the percentage of resin PU in the composite.

Keywords: Polyurethane, castor oil, bamboo, composites.

\section{Introdução}

A preocupação com a preservação do meio ambiente tem incentivado as pesquisas de novos materiais biodegradáveis e que utilizem matéria prima de fontes naturais renováveis, capazes de substituir com qualidade e apropriado desempenho os materiais poliméricos derivados dos combustíveis fósseis ${ }^{[1]}$. Entre essas matérias primas podem-se mencionar os compósitos que são o resultado da união de dois ou mais materiais de diferente natureza que proporcionam melhores propriedades ou mais adequadas do que se usados isoladamente ${ }^{[2]}$. A maioria dos polímeros utilizados na produção de compósitos é derivada de petroquímicos e tem na sua composição diversos tipos de Compostos Orgânicos Voláteis (COV's), que são substâncias tóxicas, além de cancerígenas e mutagênicas $^{[3]}$. Uma alternativa de material que não apresenta risco à saúde e ao meio ambiente é o poliuretano (PU) à base de óleo de mamona, um polímero bicomponente composto por um pré-polímero e um poliol extraído do óleo da semente da planta Ricinus communis que não emana substâncias tóxicas, além de ser um material biodegradável ${ }^{[4]}$.
O bambu é um material lignocelulósico de rápido crescimento, composto por fibras naturais de elevada resistência e apresentase como uma valiosa contribuição na produção de materiais alternativos e como reforço de matrizes ${ }^{[5,6]}$. Tais características tem despertado interesse para o seu estudo, pois possui propriedades superiores a vários materiais tradicionais, incluindo diversas espécies de madeira ${ }^{[7]}$. É um material leve, resistente, flexível, renovável, biodegradável, versátil e de baixo custo, disponível em todas as regiões brasileiras, embora ainda seja pequena a sua utilização em manufaturas se comparado principalmente aos países asiáticos $^{[8,6]}$. Sua composição química é semelhante à madeira com exceção dos extrativos alcalinos e cinzas que são maiores ${ }^{[9]}$. Anatomicamente são formados por cerca de $50 \%$ de parênquima, $40 \%$ de fibras e $10 \%$ de tecidos condutores ${ }^{[10,11]}$. Suas propriedades mecânicas variam segundo a espécie, idade, época de corte, posição dentro do colmo ${ }^{[12]}$ sendo fortemente correlacionadas a fatores como teor de umidade, densidade, composição química e sua constituição anatômica ${ }^{[10,12]}$. 
Este trabalho teve como objetivo produzir e avaliar um compósito com uma matriz de PU derivado de óleo de mamona em diferentes proporções em peso com 10, 15 e $20 \%$, reforçado com partículas de bambu da espécie Dendrocalamus giganteus e caracterizá-lo por meio de densidade; teor de umidade; absorção de água; inchamento; dureza Shore D e termogravimetria.

\section{Experimental}

\section{Material}

Poliuretano derivado de óleo de mamona (POLIBOND ${ }^{\circledR}$ ), doado pela empresa Cequil Central de Ind. Des. de Polímeros Ltda de Araraquara-SP e bambu da espécie Dendrocalamus giganteus com 4 anos de idade fornecido pelo Laboratório de Processamento de Madeira da UNESP - Bauru.

\section{Métodos}

\section{Preparo do poliuretano}

O poliuretano bicomponente é composto por um pré-polímero obtido a partir do Difenil Metano Diisocianato (MDI) e um poliol poliéster trifuncional sintetizado a partir do óleo de mamona, sendo sua maior concentração o ácido ricinoléico ${ }^{[13]}$. A preparação foi realizada na proporção de 1:1 em massa, partindo de um poliol cujo número de hidroxilas é de $250 \mathrm{mg} \mathrm{KOH/g} \mathrm{e} \mathrm{MDI} \mathrm{com} 23 \%$ de isocianato, conforme instruções do fabricante, sendo a preparação e a mistura dos componentes feita manualmente ${ }^{[14]}$.

\section{Preparação das partículas de bambu e do compósito}

Para a preparação das partículas de bambu, inicialmente os colmos foram cortados em ripas e transformados em cavacos por meio de um picador da marca Trapp e processados em moinho Marconi tipo faca, reduzindo-os em partículas menores e mais homogêneas. A classificação do tamanho foi determinada com o uso de um peneirador vibratório, sendo utilizado o material retido na peneira de 8 mesh. A secagem foi realizada em uma estufa modelo Labstore com circulação e renovação de ar forçado por um período de 24 horas a temperatura $103 \pm 2{ }^{\circ} \mathrm{C}$. Após a pesagem dos componentes em balança digital modelo Geraka BG-2000, as partículas de bambu e o PU foram previamente misturados manualmente e posteriormente passados por uma peneira com abertura de 5 mesh para homogeneização. Utilizando uma pequena caixa formadora de $200 \times 120 \times 20 \mathrm{~mm}$ a mistura foi espalhada manualmente de maneira uniforme e recoberta com um filme de acetato para evitar o contato direto com o calor dos pratos da prensa. O colchão de partículas foi prensado a uma temperatura de $90{ }^{\circ} \mathrm{C} \mathrm{e}$ uma pressão constante de $6,25 \mathrm{MPa}$ durante 5 minutos, utilizando uma prensa modelo Marconi - MA 09/AR 15.

\section{Determinação de densidade e inchamento}

A densidade foi determinada pelo método do deslocamento de água, conforme determina a norma ASTM D2395-AE ${ }^{[15]}$. Foram utilizadas amostras com $20 \mathrm{~mm}$ de diâmetro e 3,2 $\mathrm{mm}$ de espessura, secas em estufa a $103 \pm 2{ }^{\circ} \mathrm{C}$ durante um período de 24 horas. Para determinação do inchamento em água a $23{ }^{\circ} \mathrm{C}$, de acordo com a norma ASTM D570-E ${ }^{[16]}$ foram medidos, em 5 amostras, 3 pontos (meio e extremidades) com paquímetro digital marca
Western DC 60, antes e depois da saturação, sendo extraído o índice médio do inchamento do material.

\section{Determinação do teor de umidade e o índice máximo de absorção de água}

A determinação do teor de umidade nas amostras contendo 10,15 e $20 \%$ de PU foi realizada através de uma balança digital de infravermelho Marte modelo ID50. Foram analisadas 5 amostras de cada percentual em ambiente com temperatura e umidade controlados. O índice máximo de absorção de água, em percentuais, foi avaliado por diferença de massa e imersão em água destilada a $23^{\circ} \mathrm{C}$, conforme as determinações descritas na norma ASTM-D570-E ${ }^{[16]}$. As amostras foram pesadas em balança de precisão modelo Ohaus Analytical Plus em intervalos de tempo em ambiente com temperatura e umidade controladas até o ponto de saturação.

\section{Dureza Shore " $D$ "}

O equipamento utilizado para o ensaio de dureza Shore "D" foi o Durômetro Woltest de bancada modelo MP-2, com ponta aguda, segundo determina a ASTM D2240 ${ }^{[17]}$.

\section{Análise por microscopia eletrônica de varredura}

Foram obtidas imagens micrográficas para análise da morfologia do compósito utilizando o Microscópio Eletrônico de Varredura (MEV) Leo 440 empregando $20 \mathrm{kV}$ de voltagem de aceleração do feixe de elétrons.

\section{Análise termogravimétrica}

Dentre os principais componentes dos materiais lignocelulósicos estão a hemicelulose, celulose, ligninas e cinzas. O objetivo da analise termogravimétrica (TG) foi determinar a temperatura de degradação dos diversos componentes e o percentual de perda de massa das partículas de bambu, do PU e do compósito nas diferentes composições. Foi utilizada uma termobalança $D u$ Pont modelo TGA 951, acoplada a um termoanalizador TA 2000, com taxa de aquecimento de $10{ }^{\circ} \mathrm{C} / \mathrm{min}$ em atmosfera inerte com nitrogênio e faixa de temperatura de $0{ }^{\circ} \mathrm{C}$ a $800{ }^{\circ} \mathrm{C}$.

\section{Resultados e Discussão}

A Tabela 1 apresenta os resultados obtidos nos ensaios de densidade, teor de umidade, absorção de água e variação em volume, nos corpos de prova de PU/Bambu com 10, 15 e $20 \%$ de PU.

Os resultados de densidade do compósito mostraram-se superiores aos colmos de bambu, que em geral está compreendido entre os intervalos de 0,50 e $0,80 \mathrm{~g} . \mathrm{cm}^{-3[6-8]}$.

A variação da densidade (Tabela 1) ficou entre 0.85 e 0.96 g. $\mathrm{cm}^{-3}$ sem evidenciar relação direta com a incorporação de percentual de PU, o que provavelmente está relacionado à falta de homogeneidade na distribuição das partículas no processo de fabricação das amostras. A densidade é uma propriedade relevante para determinação da resistência dos materiais em geral, nos bambus pode variar de acordo com a espécie, idade e região do colmo (base, meio e topo) ${ }^{[5,6,8]}$. Nos ensaios de densidade com a espécie Dendrocalamus giganteus, foram obtidos valores de $0,76 \mathrm{~g} . \mathrm{cm}^{-3}$ no entrenó e $0,82 \mathrm{~g} \cdot \mathrm{cm}^{-3}$ na região de nó extraídas da parte basal ${ }^{[8]}$.

Os resultados de inchamento (Tabela 1), não apresentaram diferenças significativas, contudo, o aumento no teor de resina

Tabela 1. Propriedades físicas do compósito formado por PU e partículas de bambu.

\begin{tabular}{cccc}
\hline PU $(\%)$ & Densidade $\left.(\text { g.cm })^{-3}\right)$ & Teor de umidade $(\%)$ & Índice máx. absorção de água $(\%)$ \\
\hline 10 & $0.85 \pm 0.10$ & $9.9 \% \pm 0.57$ & $68.3 \pm 12.33$ \\
15 & $0.96 \pm 0.03$ & $9.2 \% \pm 0.33$ & $33.7 \pm 1.88$ \\
20 & $0.90 \pm 0.05$ & $8.8 \% \pm 0.15$ & $22.9 \pm 2.89$ \\
\hline
\end{tabular}


resultou na tendência de diminuição do inchamento, uma vez que o poliuretano, depois de curado, apresenta propriedades hidrofóbicas ${ }^{[18]}$. Estudos com a espécie Dendrocalamus giganteus na região basal, relatam $8,63 \%$ para os entrenós e $8,98 \%$ para a região dos nós ${ }^{[12]}$, sendo inferiores aos índices de inchamento do compósito. Pode-se atribuir isto à presença de irregularidades no recobrimento e no preenchimento entre as partículas de bambu, propiciando a penetração de moléculas de água por microvazios.

Em relação ao teor de umidade (Tabela 1), também não houve diferenças significativas. O bambu é um material lignocelulósico higroscópico sendo que o principal responsável pela absorção de água são os seus elementos constituintes, tais como: a celulose, a hemicelulose e os extrativos presentes nas células de parênquima e vasos condutores $^{[10,11]}$. Nos compósitos de PU/Bambu, observou-se a tendência de diminuição do teor de umidade com o aumento de percentuais de PU, efeito decorrente da impermeabilização gradual das partículas, o que pode ser atribuído à degradação térmica de alguns dos elementos constituintes do bambu que possuem grande afinidade por água, pelo uso de elevada temperatura $\left(90^{\circ} \mathrm{C}\right)$ no momento da prensagem.

Avaliando o índice de absorção de água no compósito PU/Bambu, a variação foi bem evidente com 68.3, 33.7 e $22.9 \%$

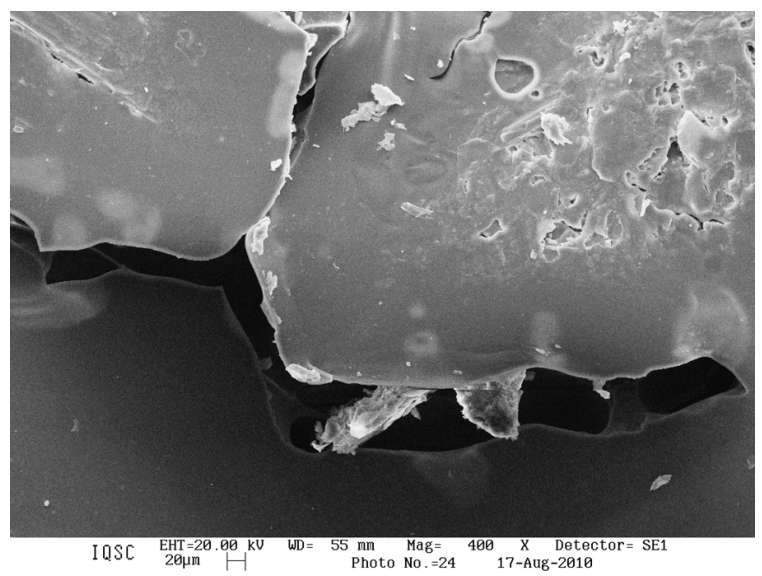

Figura 1. Micrografias por MEV $\times 400$ de uma microfissura superficial decorrente da retração das partículas no compósito com $15 \%$ de PU.

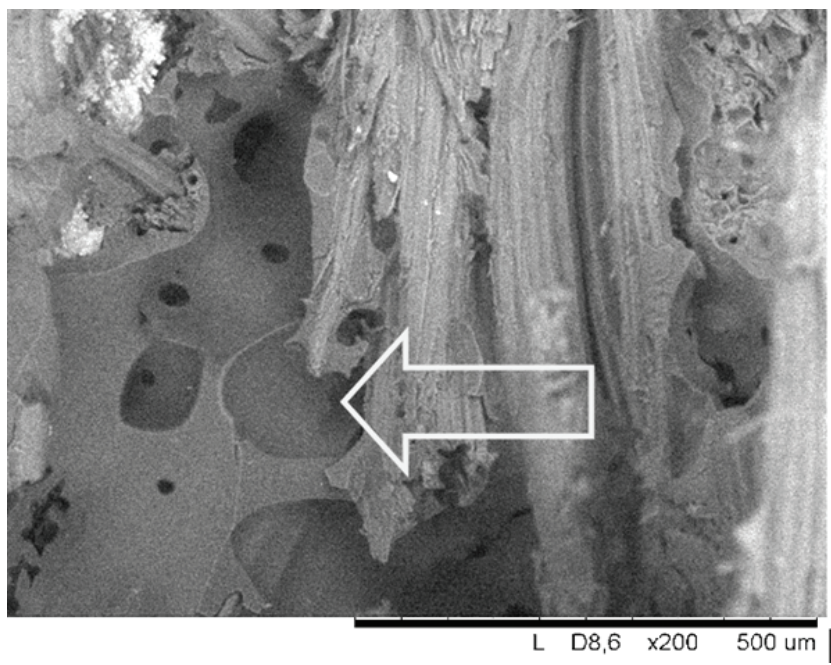

(a) para os teores de 10,15 e $20 \%$ de PU, respectivamente. Pode-se inferir que o índice de absorção de água teve uma redução drástica com o aumento no percentual de PU. Resinas bicomponentes que utilizam polióis como o óleo de mamona apresentam elevada resistência à hidrólise, devido às suas longas cadeias hidrófobas ${ }^{[18]}$. Outra possível justificativa pode estar relacionada ao aumento de adesão entre partículas e o encapsulamento destas pela resina criando barreiras à penetração de moléculas de água no seu interior.

Os bambus apresentam um comportamento mecânico ortotrópico, ou seja, baixa resistência no sentido transversal e alta resistência à tração no sentido de suas fibras ${ }^{[8]}$. No compósito $\mathrm{PU} / \mathrm{Bambu}$, em face da alta temperatura no momento da prensagem, o índice de retração das partículas possivelmente provocou diversas tensões superficiais que resultaram em microfissuras (Figura 1).

Durante o processo de polimerização entre os grupos do isocianato (NCO) e hidroxila $(\mathrm{OH})$, ocorrem reações paralelas envolvendo principalmente o $\mathrm{NCO}+\mathrm{H}_{2} \mathrm{O}$ formando Poli (uretanas/ureias) composto de alto peso molecular com excelentes propriedade mecânicas. Contudo, a reação de expansão do $\mathrm{NCO}+\mathrm{H}_{2} \mathrm{O}$ resulta na formação de uréia e a liberação de $\mathrm{CO}_{2}$ acarretando a formação de bolhas ${ }^{[18]}$, comportamento natural aplicado na fabricação de espumas, em que parte das reações resultam em ligações uréicas do tipo $-\mathrm{NC}(\mathrm{O}) \mathrm{N}-$ em lugar das ligações uretânicas ${ }^{[19]}$. A liberação de $\mathrm{CO}_{2}$ decorrente do processo de cura, somada ao desprendimento de vapor de água no momento da prensagem, são evidências da formação de defeitos. As micrografias em MEV ilustram os efeitos causados pela liberação de $\mathrm{CO}_{2}$ e a presença de vapor de água durante a cura (Figuras 2a) e a Figura 2b mostra as falhas no preenchimento da PU.

\section{Dureza Shore D}

A Dureza Shore D obtida para os compósitos de 10, 15 e $20 \%$ de PU apresentou valores médios de 65,8-66,8-67,7 respectivamente. A elevada temperatura de prensagem utilizada $\left(90{ }^{\circ} \mathrm{C}\right)$ acelerou a cinética de cura do $\mathrm{PU}$, não havendo necessidade de nenhum tratamento posterior. De acordo com o fabricante, em temperatura ambiente, a polimerização final é completada após 72 horas. Sendo a Dureza Shore D do PU de $60^{[14]}$, observou-se que a incorporação de percentuais de PU resultou na elevação da dureza superficial.

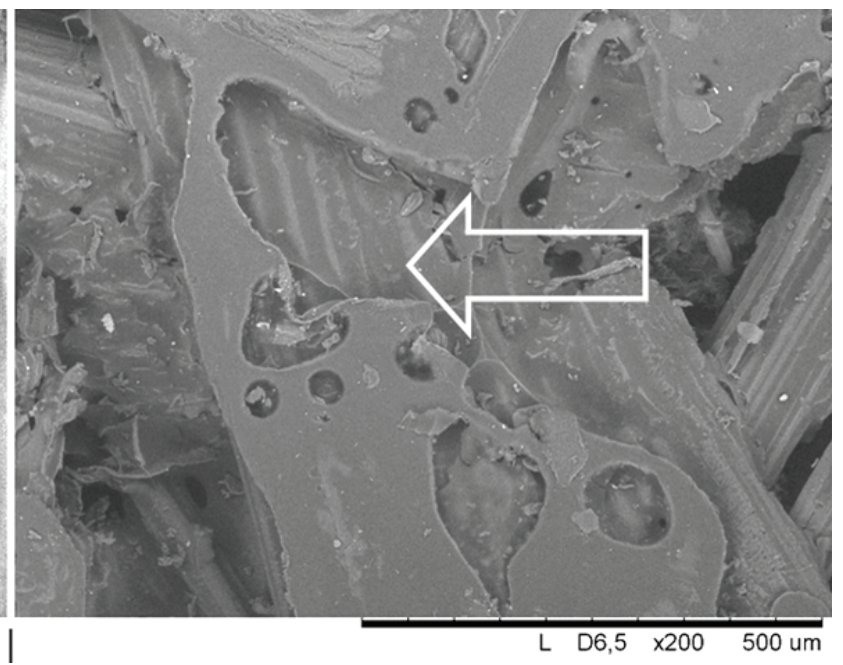

(b)

Figura 2. Micrografias por MEV × 200: a) Efeitos da liberação de $\mathrm{CO}_{2}$ e a presença de vapor de água durante a cura do PU. b) Falha no preenchimento em compósito com $20 \%$ de PU. 


\section{Análise termogravimétrica}

Em geral os eventos térmicos dos componentes lignocelulósicos apresentam-se em faixas de temperatura características ${ }^{[20]}$. A Figura 3a mostra a sobreposição das curvas termogravimétricas do PU, das partículas de bambu e do compósito com 10\%, 15 e $20 \%$ de PU. A Figura 3b apresenta a sobreposição das curvas derivativas (DTG) dos eventos térmicos dos mesmos componentes.

Ao analisar a Figura 3a, b pode-se inferir que o $\mathrm{PU}$ permanece estável até a temperatura de $250{ }^{\circ} \mathrm{C}$, evidenciando o seu caráter hidrofóbico, quando começa a perder massa até $350{ }^{\circ} \mathrm{C}$. Nesta faixa de temperatura, apresenta uma perda de $40 \%$ referente

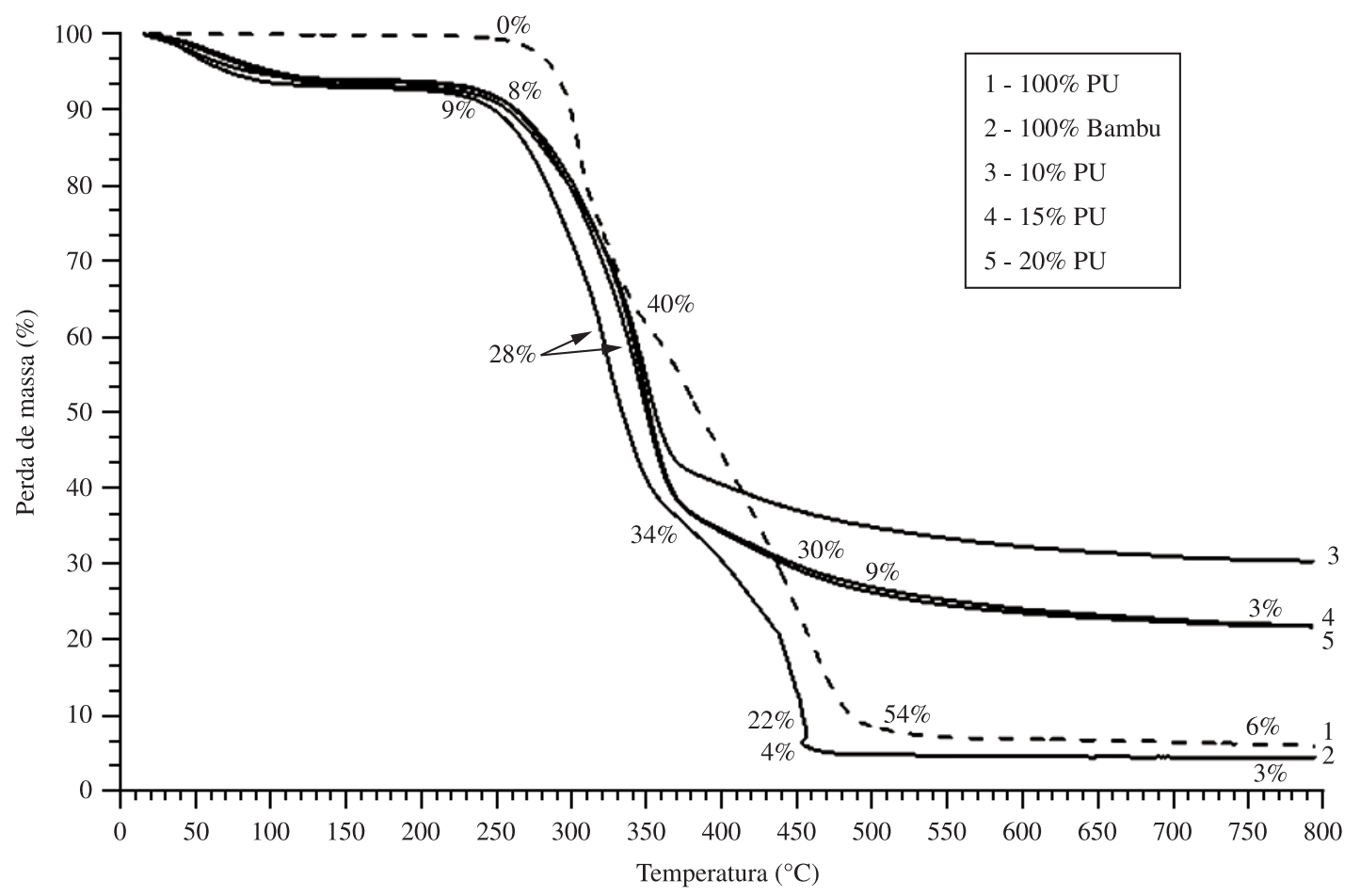

(a)

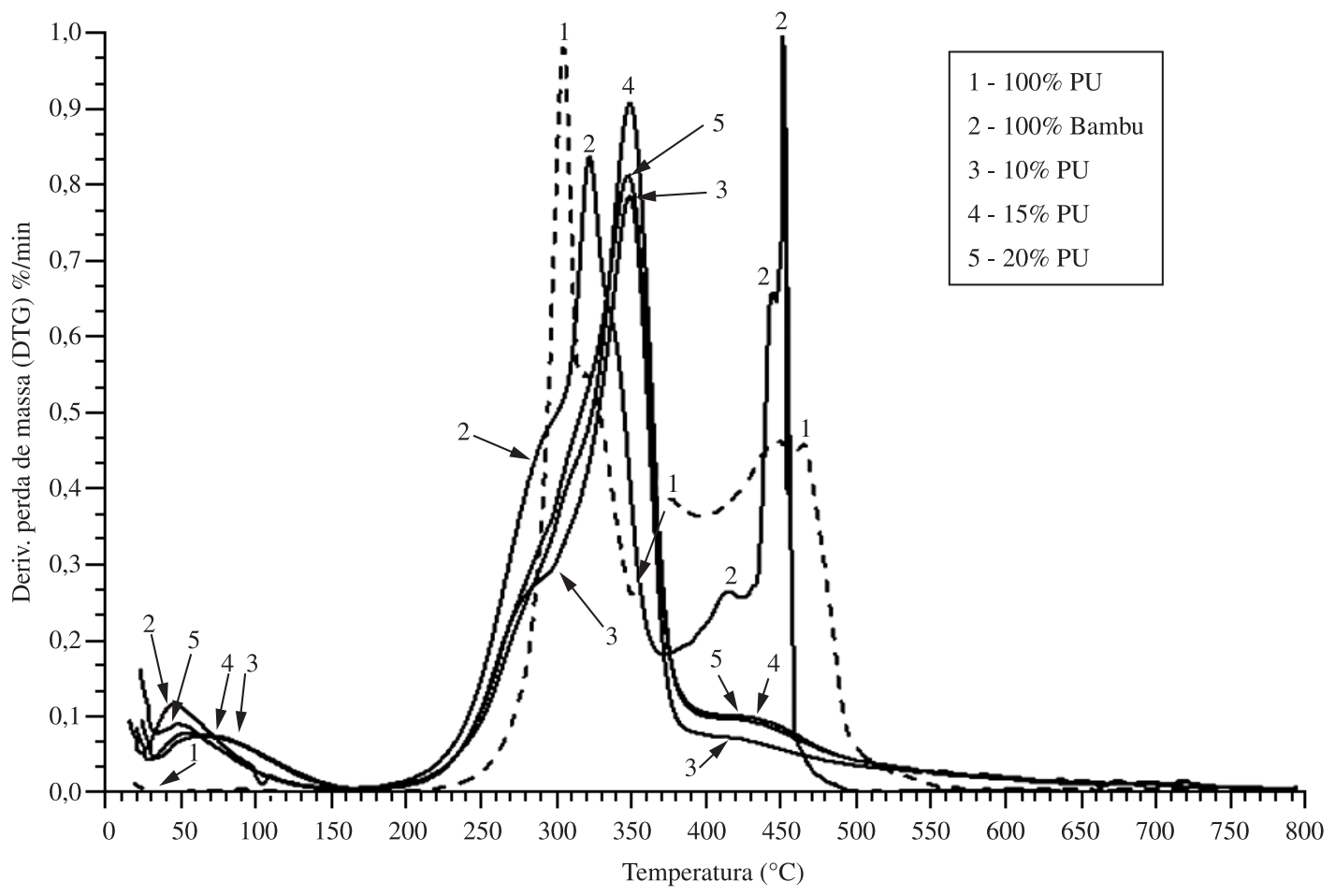

(b)

Figura 3. a) Sobreposições das curvas de TG. b) Derivadas DTG do PU, do bambu e dos compósitos com 10,15 e 20\% de PU, respectivamente. 
ao rompimento dos segmentos rígidos, quebra das ligações uretânicas e uréicas ${ }^{[19]}$. O próximo evento térmico que termina em $520{ }^{\circ} \mathrm{C}$ identifica uma perda de massa de $54 \%$ correspondente à decomposição das ligações ésteres presentes no poliol[19] ${ }^{[0}$ O resíduo resultante da decomposição térmica, ou seja, $6 \%$ está relacionado à formação de carvão (Figura 3a).

Para as partículas de bambu e o compósito com 10, 15 e $20 \%$ de PU, a perda de massa apresentou pequenas diferenças de comportamento (Figura 3a). O primeiro evento térmico inicia-se em $60{ }^{\circ} \mathrm{C}$, com perda gradual das moléculas de água das partículas de bambu e dos compósitos com 10, 15 e 20\% de PU. Em seguida, em torno de $120^{\circ} \mathrm{C}$, começa a perda de massa pela evaporação dos extrativos solúveis em água como ceras, ácidos graxos, resinas, óleos essenciais, tanino dentre outros, evento este que atinge uma temperatura em torno de $250{ }^{\circ} \mathrm{C}^{[19]}$, totalizando uma perda de massa de $10 \%$, comportamento comum nos materiais lignocelulósicos ${ }^{[20]}$.

O próximo evento térmico é a decomposição da hemicelulose que acontece no intervalo 260 a $320^{\circ} \mathrm{C}^{[20]}$, em que são perdidos em torno de $30 \%$ de massa nas partículas de bambu e nas amostras com 10,15 e $20 \%$ de PU. Nesta fase, a resina PU também começa a sua decomposição, sendo que sua perda de massa é ligeiramente maior, na faixa de $40 \%$. Geralmente os picos de transição entre a decomposição da hemicelulose e celulose são bastante discretos, sendo detectado apenas nas amostras de partículas de bambu (curva 2-Figura 3b) e no compósito com $10 \%$ de PU (curva 3-Figura 3b). A fase seguinte, decomposição da celulose, inicia-se com as partículas de bambu numa temperatura próxima de $320^{\circ} \mathrm{C}$ (curva 2-Figura 3 b) e logo em seguida nos compósitos de 10, 15 e $20 \%$ de PU a uma temperatura de $350^{\circ} \mathrm{C}$ com picos bastante pronunciados (curvas 3,4 e 5-Figura $3 \mathrm{~b}$ ) e uma perda de massa por volta de $34 \%$ (Figura 3a). Este deslocamento da degradação térmica para maiores valores de temperatura sugerem que durante a polimerização in situ da resina houve interação química entre os componentes do bambu e o PU. A penúltima fase é caracterizada pela decomposição da lignina a uma temperatura entre 430 e $460{ }^{\circ} \mathrm{C}^{[20]}$. Neste evento térmico a decomposição da lignina das partículas de bambu inicia com três picos de intensidade progressiva, como pode ser visto na Figura 3b-curva 2, com uma perda de massa em torno de $22 \%$.

O teor de resíduos do bambu e PU apresentou variações entre 3 e $6 \%$. Sob atmosfera inerte a eliminação do carbono elementar ocorre lenta e parcialmente entre 400 e $900{ }^{\circ} \mathrm{C}$ decorrente da formação de carvão, partindo-se da propagação do calor por condução a partir da superfície ${ }^{[21]}$. Em materiais compósitos no qual há uma inter-relação entre a matriz e o reforço, a degradação térmica ocorre de modo gradual devido ao recobrimento das partículas.

\section{Conclusão}

A partir das avaliações das propriedades físicas, dureza Shore $\mathrm{D}$ e das análises térmicas de compósitos elaborados por partículas de bambu da espécie Dendrocalamus giganteus associado a um poliuretano derivado de óleo de mamona, concluiu-se que a adição progressiva do poliuretano nos percentuais de 10,15 e $20 \%$ apresentou tendência de melhorias nas propriedades físicas de densidade, teor de umidade, variação de volume, destacando sensíveis reduções no índice máximo de absorção em água. Tais desempenhos são atribuídos à elevada capacidade de adesão e as características hidrofóbicas do PU.

A dureza Shore $D$ aumentou com o acréscimo de percentuais de resina nos compósitos, mas para uma adequada aplicação industrial as propriedades mecânicas do material devem ser analisadas.

As análises térmicas revelaram estabilidade dos compósitos com perdas de massa em temperaturas relativamente elevadas, sugerindo uma apropriada interação entre o bambu como reforço de matriz polimérica de poliuretano à base de óleo de mamona.

Conclui-se que o aproveitamento do resíduo de bambu associado à uma resina não poluente, produzida a partir de matéria prima renovável e de fácil obtenção é viável, em função das propriedades avaliadas, além dos benefícios ambientais e econômicos.

\section{Referências Bibliográficas}

1. Pizzi, A. - J. Adhes. Sci. Technol., 20, p.829 (2006). http://dx.doi. org/10.1163/156856106777638635

2. American Society for Testing and Materials - ASTM. - "D3878-01: Standard terminology for composite materials", ASTM International, West Conshohocken (2001).

3. International Agency for Research on Cancer. - "Press release 153" (2004).

4. Cangemi, J. M. "Biodegradação de PU derivado do óleo de mamona", Tese de Doutorado, Instituto de Química de São Carlos, Universidade de São Paulo, Brasil (2006).

5. Khosrow, G. \& Marinho A. B. - Rev. Bras. Eng. Agric. Ambient., 9, p.107 (2005). http://dx.doi.org/10.1590/S1415-43662005000100016

6. Beraldo, A. L. \& Azzini A. "Bambu: características e aplicações", Ed. Agropecuária, Guaíba (2004).

7. Rivero, L. A. "Laminado Colado e Contraplacado de Bambu", Dissertação de mestrado, Faculdade de Engenharia Agrícola, Universidade Estadual de Campinas, São Paulo, Brasil (2003).

8. Pereira, M. A. R. \& Beraldo A. L. "Bambu de corpo e alma", Ed. Canal 6, Bauru (2007).

9. Higuchi, T. - "Chemistry and biochemistry of bamboo", Wood Research Institute, Kyoto University, Kyoto (1990).

10. Liese, W. - "The anatomy of bamboo culms", INBAR - International Network for bamboo and rattan, Technical Report, p.204 (1998).

11. Liese, W. - "Bamboos - Biology, silvics, properties, utilization", GTZ, Germany, 132p. (1985).

12. Pereira, M. A. R. - "Projeto bambu: manejo e produção do bambu gigante (Dendrocalamus giganteus) cultivado na UNESP/Campus de Bauru e determinação de suas características físicas e de resistência mecânica", FAPESP (2006). Relatório FAPESP (2003/04323-7).

13. Chierice, G. O. \& Claro Neto, S. - "Aplicação Industrial do Óleo”, in: O agronegócio da mamona no Brasil, Azevedo, D. M. P. e Lima, E.F. (orgs.), Embrapa, Brasília (2001).

14. Central de Ind. Des. de Polímeros Ltda - CEQUIL. - "Polibond - adesivo polimérico". Boletim Técnico. Disponível em: <http://www.construquil. com.br/arquivos/pdf/ficha_tecnica_polibond.pdf>

15. American Society for Testing and Materials - ASTM. - "D2395-AE: Standard Test Methods for Specific Gravity of Wood and Wood-Based Materials", ASTM International, West Conshohocken (2010).

16. American Society for Testing and Materials - ASTM. - "D570-E: Standard Test Method for Water Absorption of Plastics", ASTM International, West Conshohocken (2010).

17. American Society for Testing and Materials - ASTM. - "D2240 (5): Standard Test for Rubber Property - Durometer Hardness", ASTM International, West Conshohocken (2010).

18. Vilar W. D. - "Química e Tecnologia dos PU's", 3. ed., Vilar Consultoria, Rio de Janeiro (2004).

19. Azevedo, E. C. - "Efeito da Radiação nas propriedades mecânicas do adesivo de PU derivado do óleo de mamona", Tese de doutorado, Universidade Federal do Paraná, Curitiba (2009).

20. Chen, W. H. \& Kuo P. C. - Energy, 35, p.2580 (2010). http://dx.doi. org/10.1016/j.energy.2010.02.054

21. Costa, T. M. S.; Martinelli, J. R. \& Matos, J. R. - "Análise térmica aplicada a estudos de ecoeficiência do bambu para processos de carbonização", in: Anais do XVI Congresso Brasileiro de Engenharia e Ciência dos Materiais, Porto Alegre - RS, nov./dez. (2004).

Enviado: $25 / 03 / 11$

Reenviado: $23 / 03 / 12$ Aceito: 01/04/12 